\title{
Macro-Drivers Of Gulf Co-operation Council Country's Economic Risk
}

\author{
Hassan Mounir El-Sady, Cairo University, Egypt
}

\begin{abstract}
This study provides the first empirical analysis of the Gulf Co-operation Council (GCC), which explores the macro-drivers of each country's economic risk. It examined the economic risk across GCC's countries over the period of January 2000 to December 2011. The study included all GCC countries: Kingdom of Saudi Arabia (KSA), Kuwait, United Arab of Emirates (UAE), Qatar, Sultanate of Oman (Oman), and Kingdom of Bahrain (Bahrain).

In terms of economic risk, results revealed that Kuwait and UAE represented a safe land for local and international investment to be allocated in GCC. This could be attributed to their very high rating and stability of economic systems in comparison with other GCC countries. Results also revealed that KSA, Qatar and Bahrain were considered countries with an instable economic system in comparison with other GCC countries. Moreover, findings revealed that each GCC country was a unique case in terms of its drivers of economic risk. Results also indicated that while KSA's economic risk was driven by the instability of its budget balance as a percentage of $G D P$, Kuwait's economic risk was driven by the low real GDP growth, and UAE's economic risk was driven by the instable GDP per capita. As for the economic risk of Qatar, Oman, and Bahrain, it was driven by the illiquidity of the economy as measured by the current account as a percentage of GDP.
\end{abstract}

Keywords: GCC; Country Economic Risk; Real GDP Growth; Inflation; Budget Balance; Current Account

\section{INTRODUCTION}

ountry Economic Risk received extensive interest of researchers to explore its macro-drivers. The available growing body of literature did not show enough interest to investigate the macro-drivers of the GCC country economic risk. Furthermore, researchers consider the GCC region as one Oil \& Gas economy with the same economic trends. The neglected efforts to explore the macro-drivers of GCC country economic risk did not encourage enough international capital to be allocated in GCC, except in Dubai.

This paper aims at providing the first exploratory analysis of the macro-drivers of GCC Country Economic Risk. The paper is designed to empirically investigate the macroeconomic drivers of each GCC country economic risk. The findings of this paper can assist international and local investors in their allocation of capital in GCC by providing them with a list of important and volatile macroeconomic factors that drive each GCC country economic risk. Also, GCC's policy makers can benefit from the results of this paper since it highlights the drivers of GCC's economic system that discourages international and/or local capital from being allocated in GCC, which would eventually influence the Country Investment Profile negatively.

I argue that economic risk is driven differently across GCC countries. To confirm the validity of this argument, I apply time series analysis to explore and indicate the impact of macroeconomic factors on each GCC country economic risk. Emerging relationships will be investigated, utilizing the Ordinary Lest Squared (OLS) estimator on predetermined macroeconomic factors. The study was carried out over the period of January 2000 to December 2011, and depended upon the monthly published reports by the International Country Risk Guide (ICRG) of the Political Risk Services Inc. (PRS), the World Bank. This study included all GCC countries: KSA, Kuwait, UAE, Qatar, Oman, and Bahrain. 
The First part of this paper contains the introduction. Literature review of the country risk is provided in the second part. The third part sets the research methodology and data. Analysis and discussion of the findings will be presented in the fourth part. Finally, the fifth part concludes the study and provides recommendations to investors and GCC's policy makers. Limitations and further research related to this study are highlighted in the last part.

\section{LITERATURE REVIEW}

Investigating whether the economic and political factors have any effect on the Indian risk rating, Vij and Kapoor (2007) show that the country risk is driven by economic factors more than by the political factors. Also, Vij and Kapoor (2007) indicated that different investors do invest in the Indian capital market for its low political risk. Examining the magnitude of political, financial, and economic risk and their components on a portfolio and direct investment decisions, El-Sady et al. (2003 A, B, C) pointed out that country risk measures are correlated with equity returns and capital allocation in emerging markets more than in developed markets. While Clark and Tunaru (2001) show the impact of country political risk on investment decision, Flannery and Protopapadakis (2001) point out that the allocation of capital is driven by economic risk. Examining the impact of country's macroeconomic factors on the capital market return, Diamonte et al. (1996) shows that political risk plays an important role in emerging markets as a driver of capital markets returns than it does in developed markets. Investigating the drivers of country risk and capital market development, El-Sady et al. (2009) shows that country economic, financial and political risk plays a crucial role in driving specific country risk.

In a multi-factors model, $\mathrm{Vij}$ (2005) investigated the effect of political and economic factors on its country rating. His results show that country economic and political risk can serve as good indicators of country risk rating. El-Sady et al. (2003, B) provide a strong evidence that country economic and political risk drive in Latin America's emerging markets risk and return. This evidence was also supported by El-Sady et al. (2003, A), whose results showed that the Middle East and Africa's emerging markets risk and return are driven by different subcomponents of their countries' economic, political, and financial risk. The investigation of Chen et al. (2005) of the relationship between political risk and emerging markets risk revealed that political risk plays an important role in explaining emerging markets' risk. Within the context of developed markets, El-Sady et al. (2003, C) proved the impact of country risk on developed markets risk and return.

Clark and Radu (2001), Khoury (2003), and Dar-Hsin et al. (2005) examined the relationship between country macro drivers of risk and capital allocation; they found that country risk can be used to assist investors in their selection of countries for international capital allocation. The relationship between the country risk and country return in emerging and developed markets was examined by Diamonte et al. (1996), Harvey (2004), Vij (2005), and Hsin et al. (2005). All mentioned studies that provide evidences of a strong relationship between country macro drivers of risk and country return. The relationship between capital market's risk and return and country financial risk was verified by Harvey (2004) and Hoti (2004). Country economic risk is found to have a predictive power of capital market's risk and return in the studies of Flannery and Protopapadakis (2001), Harvey (2004), Hoti (2004), and Vij (2005).

As shown in the literature review, GCC countries' risk analysis did not receive enough attention in literature. Only the study of Onour (2007) investigated the short and long-term drivers of GCC capital markets' return volatility. It shows that the change in the oil price has its way to influence major macroeconomic indicators that influence GCC stock markets risk and return. Therefore, this study provides the first extensive empirical analysis of the drivers of GCC country economic risk. Results can guide investors when allocating their capital in the GCC region. Furthermore, it puts a roadmap for GCC's policy makers to advance their economies.

\section{METHODOLOGY AND DATA}

This paper investigates empirically the drivers of each GCC country economic risk to explore whether it is formed differently by macroeconomic factors or not. It argues that there is a causal relationship between country economic risk and its macroeconomic factors. The independent variables that serve the purpose of this paper are macroeconomic factors extracted from the monthly published reports by the ICRG for KSA, Kuwait, UAE, Qatar, Oman, and Bahrain. The macroeconomic factors included in this study are; GDP per Head of Population (GDP/HP), 
Real GDP Growth (RGDPG), Annual Inflation Rate (AI), Budget Balance as a percentage of GDP (BB/GDP), and Current Account as a percentage of GDP (CA/GDP).

In this paper, time series analysis will be utilized for a comparative assessment of ICRG's economic ratings regarding GCC countries. Ordinary Least Squares (OLS) estimator is used to explore the relationship between each GCC country economic risk and its sub-macroeconomic factors, using monthly country economic risk rating over the period of January 2000 to December 2011 provided by the ICRG. Measures are ex-ante measures since it is reasonable to expect that they could have impact on the country economic risk and the capital market. Moreover, we capitalized on the analysis of variance (ANOVA) to test the adequacy of the model and to indicate the largest explanatory variables among independent variables.

This paper hypothesizes to answer the following question: "Is country economic risk driven by different macroeconomic factors across GCC countries?" The null hypothesis $\left(\mathrm{H}_{0}\right)$ and alternative hypothesis $\left(\mathrm{H}_{\mathrm{a}}\right)$ are stated as follows:

$\mathbf{H}_{\mathbf{0}}$ : GCC country economic risk cannot be explained differently across the GCC by its specific submacroeconomic factors.

$\mathbf{H}_{\mathbf{a}}$ : GCC country economic risk can be explained differently across the GCC by its specific submacroeconomic factors.

Also, this paper assumes that there is a causality relationship between GCC country economic risk and its sub-macroeconomic factors. The $\mathrm{H} 0$ and $\mathrm{Ha}$ are stated as follows:

$\mathbf{H}_{0}$ : There is no causal relationship between GCC country's economic risk and its sub-macroeconomic factors.

$\mathbf{H}_{\mathbf{a}}$ : There is a causal relationship between GCC country's economic risk and its sub-macroeconomic factors.

I argue that GCC country economic risk can be explained differently across GCC countries based on their sub-macroeconomic factors. Also, we argue that there is a causality relationship between GCC country economic risk and its sub-macroeconomic factors.

My model examines the impacts of five sources of economic risk, GDP/HP, RGDPG, AI, BB/GDP, and CA/GDP. In the model: each GCC country economic risk is a function of its sub-macroeconomic factors. Firstly, I assume that Country Economic Risk (CER) is a function of its sub- macroeconomic factors expressed by equation (1):

$$
\text { CER f(GDP/HP, RGDPG, AI, BB/GDP, CA/GDP) }
$$

Secondly, the causality relationship between CER and its sub- macroeconomic factors is expressed by the following equation (2):

$\mathrm{CER}_{\text {it }}=\alpha_{0}+\alpha_{1} \mathrm{GDP} / \mathrm{HP}_{\mathrm{it}}+\alpha_{2} \mathrm{RGDPG}_{\text {it }}+\alpha_{3} \mathrm{AI}_{\text {it }}+\alpha_{4} \mathrm{BB} / \mathrm{GDP}_{\mathrm{it}}+\alpha_{5} \mathrm{CA} / \mathrm{GDP}_{\mathrm{it}}+\varepsilon_{\text {it }}$

Where $\mathrm{CER}_{\mathrm{it}}$ is a standardized vector of country $\mathrm{i}$ economic risk at time $\mathrm{t}, \mathrm{GDP} / \mathrm{HP}_{\text {it }}$ is a standardized vector of country i GDP per Head of Population, RGDPG ${ }_{i t}$ is a standardized vectors of country i Real GDP Growth, $\mathrm{AI}_{i t}$ is a standardized vectors of country i Annual Inflation, BB/GDP ${ }_{i t}$ is a standardized vector of country i Budget Balance as percentage of GDP, CA/GDP ${ }_{\text {it }}$ is a standardized vector of country i Current Account as percentage of GDP, $\alpha$ 's represent the parameters of the model, and $\varepsilon_{\text {it }}$ is a random error term. The standardized vector value is calculated as $(\mathrm{x}-\overline{\mathrm{x}}) / \mathrm{SD}$, where $\mathrm{x}$ is a vector of observed values, $\overline{\mathrm{x}}$ is a vector of mean values, and SD is a vector of Std. deviations.

According to equation (2), all independent variables in the model's right side are non-random variables, except for the error $\left(\varepsilon_{\mathrm{it}}\right)$ term, which is assumed to follow a normal distribution with zero mean and constant 
variance $(\sigma 2) . \mathrm{CER}_{\mathrm{it}}$ is a dependent variable with the same normal distribution of the random error term $\left(\varepsilon_{\mathrm{it}}\right)$, variance $(\sigma 2)$, and the following mean:

$\alpha_{0}+\alpha_{1} \mathrm{GDP} / \mathrm{HP}_{\mathrm{it}}+\alpha_{2} \mathrm{RGDPG}_{\mathrm{it}}+\alpha_{3} \mathrm{AI}_{\mathrm{it}}+\alpha_{4} \mathrm{BB} / \mathrm{GDP}_{\mathrm{it}}+\alpha_{5} \mathrm{CA} / \mathrm{GDP}_{\mathrm{it}}+0$

It is assumed by the model that there is no correlation between the error $\left(\varepsilon_{\mathrm{it}}\right)$ term. The model represented by equation (2) is used to explore the covariance between GCC country economic risk and its sub-macroeconomic factors.

\section{DESCRIPTIVE DATA ANALYSIS}

According to ICRG rating systems, for any macroeconomic factor with $00.00 \%-49.5 \%$ of that factor's maximum points is considered a very high risk. The percentage of $50.00 \%-59.50 \%$ is considered high risk; the percentage of $60.00 \%-69.50 \%$ is considered a moderate risk; the percentage of $70.00 \%-79.50 \%$ is considered low risk, and the percentage of $80.00 \%-100 \%$ is considered a very low risk. Tables (1) to (7) provide the descriptive statistics for the whole GCC economic risk as well as for each GCC country.

According to the ICRG, the GCC region enjoys a very high country economic risk rating with the mean of 44.03 points $(86.06 \%$ ), which classifies GCC with very low economic risk. This rating is driven mainly by GCC's GDPG, CA/GDP, and BB/GDP with their high mean of $89.70 \%, 87.53 \%$ and $83.50 \%$ respectively. Although GCC is classified as a region with very low economic risk, the minimum of 34 points, counting for $68 \%$, indicates that GCC was suffering, sometimes, from high economic risk over the study period. The high Std. deviation of 3.32 points over the study period reveals that GCC's economic systems are instable. This instability is driven mainly by the CA/GDP and BB/GDP, since they have the highest Std. deviation of 2.20 and 1.19 respectively.

Even though Table (1) shows that GCC economic risk is very low as represented by its high rating, the AI and GDP/HP contribute negatively to the GCC economic risk rating with their low mean of $62.47 \%$ and $78.60 \%$ respectively. The high economic risk related to inflation might discourage foreign capital from being allocated in GCC.

Table 1: Descriptive Statistics of GCC's Economic Risk

\begin{tabular}{lccccccc}
\hline \multicolumn{1}{c}{ Macroeconomic Factors } & $\begin{array}{c}\text { Rating } \\
\text { (Points) }\end{array}$ & $\begin{array}{c}\text { Range } \\
\text { (Points) }\end{array}$ & $\begin{array}{c}\text { Min. } \\
\text { (Points) }\end{array}$ & $\begin{array}{c}\text { Max. } \\
\text { (Points) }\end{array}$ & $\begin{array}{c}\text { Mean } \\
\text { (Points) }\end{array}$ & $\begin{array}{c}\text { Mean } \\
(\%)\end{array}$ & $\begin{array}{c}\text { Std. } \\
\text { Deviation }\end{array}$ \\
\hline CER & 50 & 15.50 & 34.00 & 49.50 & 44.03 & $86.06 \%$ & 3.32 \\
GDP/HP & 5 & 1.50 & 3.00 & 5.00 & 3.93 & $78.60 \%$ & 0.24 \\
GDPG & 10 & 4.00 & 6.00 & 10.00 & 8.97 & $89.70 \%$ & 0.89 \\
AI & 15 & 6.00 & 5.50 & 11.50 & 9.37 & $62.47 \%$ & 0.71 \\
BB/GDP & 10 & 5.50 & 4.50 & 10.00 & 8.35 & $83.50 \%$ & 1.19 \\
CA/GDP & 15 & 5.50 & 9.50 & 15.00 & 13.13 & $87.53 \%$ & 2.20 \\
\hline
\end{tabular}

Source: Author's calculation is based on ICRG's published data for the period of Jan. 2000 to Dec. 2011.

Table (2) discloses the drivers of Kingdom of Saudi Arabia (KSA) economic risk. As classified by the ICRG, KSA enjoys a very low economic risk, on average, as measured by the mean of 43.18 points (86.3\%). KSA's Std. deviation of economic risk is very high and counts for 4.31 points of expected value for the country economic risk. The high Std. deviation is explained by the range of 14 points between the minimum of 34.5 and the minimum of 48.5 points. The very high Std. deviation of KSA's economic risk is driven by the high volatility of KSA's BB/GDP and CA/GDP with 2.02 and 1.75 points respectively. CA/GDP and BB/GDP have the highest ranges among the rest of the factors that compose KSA's economic risk with average of 5.5 points for both of them. Also, over the study period and in terms of KSA's mean economic risk rating, AI and GDP/HP show moderate risk with mean rating percentage of $65.32 \%$ and $68.27 \%$ respectively, driving KSA's economic risk rating down.

Also, Table (2) shows that GDPG/HP and AI contribute to the stability of KSA economic system since they have the minimum volatility measured by the Std. deviation of 0.19 and 0.53 points among other economic risk factors. It is interesting to point out that the low Std. deviation of KSA's GDP/HP and AI are driven by the low and stable rating points with the narrowest range of 0.50 points of all sub-macroeconomic factors, but are not driven by high rating points of these two sub-macroeconomic factors. 
Table 2: Descriptive Statistics of Kingdom of Saudi Arabia's Economic Risk

\begin{tabular}{lccccccc}
\hline \multicolumn{1}{c}{ Macroeconomic Factors } & $\begin{array}{c}\text { Rating } \\
\text { (Points) }\end{array}$ & $\begin{array}{c}\text { Range } \\
\text { (Points) }\end{array}$ & $\begin{array}{c}\text { Min. } \\
\text { (Points) }\end{array}$ & $\begin{array}{c}\text { Max. } \\
\text { (Points) }\end{array}$ & $\begin{array}{c}\text { Mean } \\
\text { (Points) }\end{array}$ & $\begin{array}{c}\text { Mean } \\
(\%)\end{array}$ & $\begin{array}{c}\text { Std. } \\
\text { Deviation }\end{array}$ \\
\hline CER & 50 & 14.00 & 34.50 & 48.50 & 43.19 & $86.38 \%$ & 4.31 \\
GDP/HP & 5 & 0.50 & 3.00 & 3.50 & 3.41 & $68.27 \%$ & 0.19 \\
GDPG & 10 & 4.00 & 6.00 & 10.00 & 8.14 & $81.44 \%$ & 1.17 \\
AI & 15 & 0.50 & 9.50 & 10.00 & 9.80 & $65.32 \%$ & 0.53 \\
BB/GDP & 10 & 5.50 & 4.50 & 10.00 & 8.24 & $82.36 \%$ & 2.02 \\
CA/GDP & 15 & 5.50 & 9.50 & 15.00 & 13.60 & $90.64 \%$ & 1.75 \\
\hline
\end{tabular}

Source: Author's calculation is based on ICRG's published data for the period of Jan. 2000 to Dec. 2011.

Regarding the State of Kuwait, Table (3) reveals that Kuwait has a stable economic risk with Std. deviation of 1.83 points. This stability is driven by the high minimum rate of 42.5 points $(85 \%)$, which discloses that Kuwait was enjoying a very stable economic system with a very low economic risk over the study period. The mean of the economic risk rating counts for 46.40 points $(92.8 \%)$ allows Kuwait to be in the category of very low economic risk. This stability of Kuwait economic system is reflected in high rating, and very low economic risk is driven mainly by CA/GDP with zero Std. deviation. These figures indicate that Kuwait enjoy a very liquid economy with huge surplus. Also, GDP/HP, AI, and BB/GDP with Std. deviation of 0.32, 0.42, and 0.58 points respectively play major roles in positioning Kuwait as the safest GCC economy with very low economic risk.

Although Kuwait is assigned a very low economic risk, it has a major volatility fluctuating issue where GDPG has a Std. deviation of 1.33 points with minimum rating points of 5.00 (50\%). The stable high annual inflation (AI) contributes positively to the stability of Kuwait economic risk with its very low Std. deviation of 0.42 points; however, it contributes negatively to the economic risk rating with mean of $9.39(62.63 \%)$, which categorizes the $\mathrm{AI}$ as moderate risk.

Table 3: Descriptive Statistics of Kuwait's Economic Risk

\begin{tabular}{|c|c|c|c|c|c|c|c|}
\hline Macroeconomic Factors & $\begin{array}{l}\text { Rating } \\
\text { (Points) }\end{array}$ & $\begin{array}{c}\text { Range } \\
\text { (Points) }\end{array}$ & $\begin{array}{c}\text { Min. } \\
\text { (Points) }\end{array}$ & $\begin{array}{c}\text { Max. } \\
\text { (Points) }\end{array}$ & $\begin{array}{c}\text { Mean } \\
\text { (Points) }\end{array}$ & $\begin{array}{c}\text { Mean } \\
(\%)\end{array}$ & $\begin{array}{c}\text { Std. } \\
\text { Deviation }\end{array}$ \\
\hline CER & 50 & 7.00 & 42.50 & 49.50 & 46.40 & $92.81 \%$ & 1.83 \\
\hline GDP/HP & 5 & 1.00 & 4.00 & 5.00 & 4.29 & $85.77 \%$ & 0.32 \\
\hline GDPG & 10 & 5.00 & 5.00 & 10.00 & 8.14 & $81.44 \%$ & 1.33 \\
\hline AI & 15 & 2.00 & 8.00 & 10.00 & 9.39 & $62.63 \%$ & 0.42 \\
\hline BB/GDP & 10 & 1.50 & 8.50 & 10.00 & 9.58 & $95.77 \%$ & 0.58 \\
\hline CA/GDP & 15 & 0.00 & 15.00 & 15.00 & 15.0 & $100 \%$ & 0.00 \\
\hline
\end{tabular}

Source: Author's calculation is based on ICRG's published data for the period of Jan. 2000 to Dec. 2011.

Descriptive statistics reported in Table (4) show the steadiness of United Arab Emirates (UAE) economic system with its very low Std. deviation of 1.35 points and mean of 45.74 points (91.48\%). These figures qualify UAE as one of the countries with very low economic risk. The very low economic risk of UAE was driven by the CA/GDP and GDPG with mean of 14.6 points $(97.34 \%)$ and 9.15 points $(91.49 \%)$ respectively, followed by $\mathrm{BB} / \mathrm{GDP}$ and GDP/HP with mean of 8.49 points $(84.90 \%)$ and 4.19 points $(83.85 \%)$ respectively. In contrast, annual inflation (AI), as shown in Table (4), contributes negatively to the stability of UAE's economic system and economic risk, rating with its high Std. deviation of 1.8 points and low mean rating points of 8.49 of 15 points $(58.01 \%)$.

Table 4: Descriptive Statistics of United Arab Emirates' Economic Risk

\begin{tabular}{lccccccc}
\hline \multicolumn{1}{c}{ Macroeconomic Factors } & $\begin{array}{c}\text { Rating } \\
\text { (Points) }\end{array}$ & $\begin{array}{c}\text { Range } \\
\text { (Points) }\end{array}$ & $\begin{array}{c}\text { Min. } \\
\text { (Points) }\end{array}$ & $\begin{array}{c}\text { Max. } \\
\text { (Points) }\end{array}$ & $\begin{array}{c}\text { Mean } \\
\text { (Points) }\end{array}$ & $\begin{array}{c}\text { Mean } \\
(\%)\end{array}$ & $\begin{array}{c}\text { Std. } \\
\text { Deviation }\end{array}$ \\
\hline CER & 50 & 6.00 & 35.50 & 41.50 & 45.74 & $91.48 \%$ & 1.35 \\
GDP/HP & 5 & 0.50 & 4.50 & 5.00 & 4.19 & $83.85 \%$ & 0.17 \\
GDPG & 10 & 3.00 & 7.00 & 10.00 & 9.15 & $91.49 \%$ & 0.88 \\
AI & 15 & 6.00 & 5.50 & 11.50 & 8.70 & $58.01 \%$ & 1.80 \\
BB/GDP & 10 & 2.50 & 7.50 & 10.00 & 8.49 & $84.90 \%$ & 1.04 \\
CA/GDP & 15 & 4.00 & 11.00 & 15.00 & 14.60 & $97.34 \%$ & 0.88 \\
\hline
\end{tabular}

Source: Author's calculation is based on ICRG's published data for the period of Jan. 2000 to Dec. 2011. 
As shown in Table (5), Qatar can be classified as a country with an instable economic system. The economic risk rate of 48 points as maximum, 34.5 points as minimum, with a range of 13.5 points resulted in the very high Std. deviation of 5.28 points. Thus, Qatar would be categorized as a country with an unstable economic system. Table (5) indicates that Qatar is within the range of very low economic risk, with its mean of 44.13 points $(88.27 \%)$.

The high rate of Qatar's economic risk, showing a very low economic risk, is driven by GDP/HP and GDPG of $98.56 \%$ and $92.60 \%$ respectively. This result is supported by the fact that over the last decade, Qatar was classified as one of the top world economies with the highest GDP/HP and GDPG. Still, Qatar has a major volatility issue as noted in Table (5), which is driven by the CA/GDP showing Qatar as an illiquid economy. The high and stable $\mathrm{AI}$ is another issue of concern that contributes positively to the stability of Qatar's economic risk with its low Std. deviation of 0.85 points, but contributes negatively to Qatar's economic risk rating with its mean of $59.47 \%$.

Table 5: Descriptive Statistics of Qatar's Economic Risk

\begin{tabular}{lccccccc}
\hline \multicolumn{1}{c}{ Macroeconomic Factors } & $\begin{array}{c}\text { Rating } \\
\text { (Points) }\end{array}$ & $\begin{array}{c}\text { Range } \\
\text { (Points) }\end{array}$ & $\begin{array}{c}\text { Min. } \\
\text { (Points) }\end{array}$ & $\begin{array}{c}\text { Max. } \\
\text { (Points) }\end{array}$ & $\begin{array}{c}\text { Mean } \\
\text { (Points) }\end{array}$ & $\begin{array}{c}\text { Mean } \\
(\%)\end{array}$ & $\begin{array}{c}\text { Std. } \\
\text { Deviation }\end{array}$ \\
\hline CER & 50 & 13.50 & 34.50 & 48.00 & 44.13 & $88.27 \%$ & 5.28 \\
GDP/HP & 5 & 0.50 & 4.50 & 5.00 & 4.93 & $98.56 \%$ & 0.18 \\
GDPG & 10 & 2.50 & 7.50 & 10.00 & 9.26 & $92.60 \%$ & 0.83 \\
AI & 15 & 2.50 & 7.50 & 10.00 & 8.92 & $59.47 \%$ & 0.85 \\
BB/GDP & 10 & 2.00 & 8.00 & 10.00 & 8.37 & $83.65 \%$ & 0.78 \\
CA/GDP & 15 & 10.00 & 5.00 & 15.00 & 12.46 & $83.08 \%$ & 4.21 \\
\hline
\end{tabular}

Source: Author's calculation is based on ICRG's published data for the period of Jan. 2000 to Dec. 2011.

According to Table (6), Oman enjoys a very low economic risk with mean of 43.27 points $(86.56 \%)$. This high rating is driven mainly by CA/GDP and GDPG, with mean of 13.11 points $(87.43 \%)$ and 8.95 points (89.59\%) respectively. Although CA/GDP is the main driver of high rank of Oman's risk rating, with its mean of 13.11 points $(87.43 \%)$, it is considered the main driver of Oman's economic system instability with its Std. deviation of 1.79 points. Furthermore, and as shown in Table (6), although GDP/HP and AI contribute to the stability of Oman's economic system, as explained by their very low Std. deviation of 0.23 and 0.47 points respectively, they affect Oman's economic risk rating negatively as a result of their low mean of $62.88 \%$ and $65.22 \%$, respectively.

Table 6: Descriptive Statistics of Sultanate of Oman's Economic Risk

\begin{tabular}{lccccccc}
\hline Macroeconomic Factors & $\begin{array}{c}\text { Rating } \\
\text { (Points) }\end{array}$ & $\begin{array}{c}\text { Range } \\
\text { (Points) }\end{array}$ & $\begin{array}{c}\text { Min. } \\
\text { (Points) }\end{array}$ & $\begin{array}{c}\text { Max. } \\
\text { (Points) }\end{array}$ & $\begin{array}{c}\text { Mean } \\
\text { (Points) }\end{array}$ & $\begin{array}{c}\text { Mean } \\
(\%)\end{array}$ & $\begin{array}{c}\text { Std. } \\
\text { Deviation }\end{array}$ \\
\hline CER & 50 & 8.00 & 39.00 & 47.00 & 43.28 & $86.56 \%$ & 2.56 \\
GDP/HP & 5 & 0.50 & 3.00 & 3.50 & 3.14 & $62.88 \%$ & 0.23 \\
GDPG & 10 & 3.00 & 7.00 & 10.00 & 8.96 & $89.60 \%$ & 0.84 \\
AI & 15 & 2.00 & 8.00 & 10.00 & 9.78 & $65.22 \%$ & 0.47 \\
BB/GDP & 10 & 3.50 & 6.50 & 10.00 & 8.33 & $83.27 \%$ & 0.90 \\
CA/GDP & 15 & 5.00 & 10.00 & 15.00 & 13.11 & $87.43 \%$ & 1.79 \\
\hline
\end{tabular}

Source: Author's calculation is based on ICRG's published data for the period of Jan. 2000 to Dec. 2011.

Table (7) shows that Bahraini economy was showing a steady growth over the study period with high mean of 9.17 points $(91.68 \%)$ and low Std. deviation of 0.29 points. Bahrain's economy is ranked as one of the economies with very low risk on average as measured by the mean of 41.42 points $(82.84 \%)$. As reported in Table (7), Bahrain enjoys very low economic risk with its mean of 41.42 points $(82.84 \%)$. This very high rating is driven by GDPG of 9.17 points (91.68\%). The macroeconomic factors of CA/GDP, GDP/CA, and BB/GDP fall in the range of moderate economic risk with their average points of $11.99(79.94 \%), 3.59(71.83 \%)$, and $7.06(70.58 \%)$ respectively. In addition, Table (7) shows that GDPG/HP, GDP, and AI contribute to the stability of Bahrain's economic system since they have the minimum volatility measured by the Std. deviation of $0.35,0.29$, and 0.21 points among other economic risk factors. 
Table 7: Descriptive Statistics of Kingdom of Bahrain's Economic Risk

\begin{tabular}{lccccccc}
\hline Macroeconomic Factors & $\begin{array}{c}\text { Rating } \\
\text { (Points) }\end{array}$ & $\begin{array}{c}\text { Range } \\
\text { (Points) }\end{array}$ & $\begin{array}{c}\text { Min. } \\
\text { (Points) }\end{array}$ & $\begin{array}{c}\text { Max. } \\
\text { (Points) }\end{array}$ & $\begin{array}{c}\text { Mean } \\
\text { (Points) }\end{array}$ & $\begin{array}{c}\text { Mean } \\
(\%)\end{array}$ & $\begin{array}{c}\text { Std. } \\
\text { Deviation }\end{array}$ \\
\hline CER & 50 & 12.50 & 37.00 & 49.50 & 41.42 & $82.84 \%$ & 4.56 \\
GDP/HP & 5 & 1.50 & 3.50 & 5.00 & 3.59 & $71.83 \%$ & 0.35 \\
GDPG & 10 & 1.00 & 9.00 & 10.00 & 9.17 & $91.68 \%$ & 0.29 \\
AI & 15 & 0.50 & 9.50 & 10.00 & 9.61 & $64.07 \%$ & 0.21 \\
BB/GDP & 10 & 4.50 & 5.50 & 10.00 & 7.06 & $70.58 \%$ & 1.85 \\
CA/GDP & 15 & 5.50 & 9.50 & 15.00 & 11.99 & $79.94 \%$ & 2.35 \\
\hline
\end{tabular}

Source: Author's calculation is based on ICRG's published data for the period of Jan. 2000 to Dec. 2011.

Reported results shown by Tables (1) through (7) conclude that GCC countries enjoy very low economic risk. Kuwait is showing its safe economic environment with the highest rating of 46.40 points $(92.81 \%)$ among other GCC countries. Kuwait is followed by UAE, Oman, Qatar, KSA, and Bahrain with mean rating of 45.74 points (91.48\%), 44.13 points $(88.27 \%), 43.27$ points $(86.56 \%), 43.18$ points $(86.38 \%)$, and 41.41 points $(82.84 \%)$ respectively. In terms of economic system stability, UAE is the most stable GCC economy with its low Std. deviation of 1.35 points followed by Kuwait, Oman, KSA, Bahrain, and Qatar with Std. deviation of 1.83, 2.56, $4.3109,4.56$, and 5.27 points respectively. Tables (1) to (7) show cogently that GCC country risk is driven differently by its sub-macroeconomic factors. It is evidenced that the very low economic risk of Kuwait, KSA, and UAE is driven by CA/GDP, by GDP/HP in Qatar, and by GDPG in Oman and Bahrain. The common macroeconomic factor that drives GCC economic risk is annual inflation (AI), which is found to be the main driver of all GCC country economic risks with their low rates. This is explained by the fact that GCC economies are pegged to US dollar; therefore the GCC inflation is imported through exchange rate. It is shown by Tables (1) to (7) that the instability of GCC economies is driven by BB/GDP in KSA and Bahrain, by GDPG in Kuwait, by GDP/HP in UAE, and by CA/GDP in Qatar and Oman, as measured by Std. deviation.

In conclusion, exposed results by Tables (1) through (7) lead us to reject the null hypothesis that "GCC country economic risk cannot be explained differently across the GCC by its specific sub-macroeconomic factors" since they are driven and explained differently.

\section{SUMMARY AND ANALYSIS OF THE EMPIRICAL RESULTS}

In modelling the relationship between country economic risk and its components, coefficients of equation (2) are estimated for each of the GCC countries as reported in Table (8). Table (8) reports the results of the OLS estimation for the GCC countries' economic risk. Results show a positive and significant relationship between country economic risk and its sub-macroeconomic factors of GDP/HP, RGDPG, AI, BB/GDP, and CA/GDP. All results are significant at the $1 \%$ significance level.

Results reported in panel (A) of Table (8) show that KSA's economic risk has a significant and positive relationship with $\mathrm{CA} / \mathrm{GDP}, \mathrm{BB} / \mathrm{GDP}$, and GDPG, which explains $33.16 \%, 32.20 \%$ and $22.27 \%$ of the Kingdom's economic risk. Although GDP/HP and AI have positive and significant relationship with KSA's economic risk, they explain only $15.62 \%$ and $15.32 \%$ of the KSA's economic risk, respectively. Also, results reported in panel (A) of Table (8) indicate that a one unit increase in BB/GDP and CA/GDP will improve the KSA's economic risk rating by $76.43 \%$ and $65.62 \%$ of that unit respectively; while a one unit increase in GDPG, GDP/HP, and AI will subsequently increase the KSA's economic risk rating by $39.77 \%, 19.34 \%$, and $14.34 \%$ of that unit respectively. Moreover, the results indicate that the most influencing source of the KSA's economic risk is CA/GDP, followed by BB/GDP, GDPG, GDP/HP and AI.

Panel (B) of Table (8) reports the results of the OLS estimation for Kuwait's economic risk. It reveals that Kuwait's economic risk has a significant and positive relationship with GDPG, which explains $66.36 \%$ of Kuwait's economic risk. It is followed by GDP/HP, which explains $21.54 \%$ of the country's economic risk. AI and BB/GDP have a significant, but a less positive, relationship with Kuwait's economic risk; they explain only $9.36 \%$ and $5.74 \%$ of Kuwait's economic risk respectively. Reported results in panel (B) of Table (8) state that a one unit increase in GDPG will improve Kuwait's economic risk rating by $72.44 \%$ of that unit; while a one unit increase in BB/GDP, $\mathrm{AI}$, and GDP/HP will increase the economic risk rating by $31.49 \%, 22.68 \%$, and $17.28 \%$ of that unit respectively. In 
terms of the most influencing source of Kuwait's economic risk, results indicate that GDPG, which explains $66.36 \%$ of Kuwait's economic risk, is the most influencing factor. It is followed by GDP/HP, which explains $21.54 \%$ of Kuwait's economic risk, AI, which explains $9.36 \%$, and finally BB/GDP, which explains $5.74 \%$ of Kuwait's economic risk. For CA/GDP, the model did not show any significant relationship with Kuwait's economic risk since it is constant over the study period with zero Std. deviation.

Table 8: GCC Countries' OLS Economic Risk Estimates

\begin{tabular}{|c|c|c|c|c|c|c|}
\hline & & GDP/HP & GDPG & AI & BB/GDP & CA/GDP \\
\hline \multirow[t]{3}{*}{ Panel (A): KSA } & $\alpha$ & $0.1934 * * *$ & $0.3977 * * *$ & $0.1434 * * *$ & $0.7643^{* * *}$ & $0.6562 * * *$ \\
\hline & Seq. SS & 15.62 & 22.27 & 15.35 & 32.20 & 33.16 \\
\hline & $P$-Value & 0.000 & 0.000 & 0.000 & 0.000 & 0.000 \\
\hline \multirow[t]{3}{*}{ Panel (B): Kuwait } & $\alpha$ & $0.1728 * * *$ & $0.7244 * * *$ & $0.2268 * * *$ & $0.3149 * * *$ & N/A \\
\hline & Seq. SS & 21.54 & 66.36 & 9.36 & 5.74 & N/A \\
\hline & $P$-Value & 0.000 & 0.000 & 0.000 & 0.000 & N/A \\
\hline \multirow[t]{3}{*}{ Panel (C): UAE } & $\alpha$ & $0.9711 * * *$ & $0.1129 * * *$ & $0.1464 * * *$ & $0.1281 * * *$ & $0.1528 * * *$ \\
\hline & Seq. SS & 99.59 & 1.25 & 0.01 & 0.91 & 0.60 \\
\hline & $P$-Value & 0.000 & 0.000 & 0.000 & 0.000 & 0.000 \\
\hline \multirow[t]{3}{*}{ Panel (D): Qatar } & $\alpha$ & $0.0334 * * *$ & $0.1573 * * *$ & $0.1608 * * *$ & $0.1471 * * *$ & $0.7976 * * *$ \\
\hline & Seq. SS & 54.81 & 22.75 & 1.81 & 13.13 & 10.51 \\
\hline & $P$-Value & 0.000 & 0.000 & 0.000 & 0.000 & 0.000 \\
\hline \multirow[t]{3}{*}{ Panel (E): Oman } & $\alpha$ & $0.0888 * * *$ & $0.3295 * * *$ & $0.1818^{* * *}$ & $0.3520 * * *$ & $0.6993 * * *$ \\
\hline & Seq. SS & 2.67 & 40.27 & 1.78 & 22.67 & 35.61 \\
\hline & $P$-Value & 0.000 & 0.000 & 0.000 & 0.000 & 0.000 \\
\hline \multirow[t]{3}{*}{ Panel (F): Bahrain } & $\alpha$ & $0.0775 * * *$ & $0.0641 * * *$ & $0.0457 * * *$ & $0.4046 * * *$ & $0.5149 * * *$ \\
\hline & Seq. SS & 18.83 & 73.41 & 0.15 & 2.14 & 8.47 \\
\hline & $P$-Value & 0.000 & 0.000 & 0.000 & 0.000 & 0.000 \\
\hline
\end{tabular}

The results of UAE reported in Table (8) panel (C) show that UAE's economic risk has a significant positive relationship with its macro-drivers. Results indicate that GDP/HP is the main driver of UAE's economic risk, where one unit increase in GDPG/HP will advance UAE's economic risk rating by $97.11 \%$ of that unit. GDPG, $\mathrm{AI}, \mathrm{BB} / \mathrm{GDP}$, and CA/GDP are less important in advancing UAE's economic risk rating, where one unit increase for any of them will improve the economic risk rating by $11.3 \%, 14.64 \%, 12.81 \%$, and $15.28 \%$ of that unit respectively. Results indicate that the most influencing source of UAE's economic risk is GDPG/HP, which explains $99.59 \%$ of UAE's economic risk.

Qatar's results, as reported in Table (8) panel (D), show a significant positive relationship between Qatar's economic risk and its sub-macroeconomic factors. Results reveal that GDP/HP has the highest explanatory power; it explains $54.81 \%$ of Qatar's economic risk. The GDPG has a moderate explanatory power for Qatar's economic risk; it can explain $22.75 \%$ of it. BB/GDP and CA/GDP have low explanatory power; they can explain $13.13 \%$ and $10.51 \%$, respectively, of Qatar's economic risk. Reported results in panel (D) of Table (8) clarify that a one unit increases in Qatar's CA/GDP will advance the country's economic risk rating by $79.76 \%$ of that unit, while a one unit increase in GDPG, AI, and BB/GDP will improve the economic risk rating by $15.73 \%, 16.08 \%$, and $14.71 \%$, respectively, of that unit. Furthermore, panel (D) of Table (8) indicates that the most influencing source of Qatar's economic risk is GDP/HP, which explains $54.81 \%$. It is followed by GDPG, which explains $22.75 \%$. Then, BB/GDP, which explains $13.13 \%$, and, finally, CA/GDP, which explains $10.51 \%$ of Qatar's economic risk.

It is shown in Table (8) panel (E) that Oman's economic risk has a significant positive relationship with GDP/HP, GDPD, AI, BB/GDP, and CA/GDP. The results suggest that a one unit increase in CA/GDP will improve Oman's economic risk rating by $69.93 \%$ of that unit, while a one unit increase in BB/GDP, GDP/HP, AI, and GDP/HP will improve the economic risk rating by $35.20 \%, 32.95 \%, 18.18 \%$, and $8.88 \%$ of that unit respectively. In terms of the most influencing source of the Oman's economic risk, results indicate that GDPG, which explains $40.27 \%$ of Oman's economic risk, is the most influencing factor. Then, it is followed by CA/GDP, which explains $35.61 \%$. BB/GDP explains $22.67 \%$ of Oman's economic risk. GDP/HP and AI have the lowest influencing source on Oman's economic risk, where they explain only $2.67 \%$ and $1.78 \%$, respectively, of Oman's economic risk. 
Panel (F) of Table (8) shows that Bahrain's economic risk has a significant positive relationship with the macro-drivers of the kingdom economic risk. Results indicate that CA/GDP and BB/GDP are the main drivers of Bahrain's economic risk, where a one unit increase in CA/GDP and BB/GDP will advance Bahrain's economic risk rating by $51.49 \%$ and $40.46 \%$, respectively, of that unit. GDPG/HP, GDPG, and AI are less important in advancing Bahrain's economic risk rating, where a one unit increase for any of them will improve the economic risk rating by only $7.75 \%, 6.41 \%$, and $4.57 \%$ of that unit respectively. Results indicate that Bahrain's economic risk is highly influenced by $\mathrm{CA} / \mathrm{GDP}$ and $\mathrm{BB} / \mathrm{GDP}$, which can drive $51.49 \%$ and $40.46 \%$, respectively, of Bahrain's economic risk.

The analysis of variance (ANOVA) has shown that, at any significance level, economic risk of all GCC countries is driven differently by the five sub-macroeconomic factors included in the study.

\section{DISCUSSION AND CONCLUSIONS}

This paper provides the first analysis of GCC country economic risk. The study utilized time series analysis technique using SPSS to calculate the range, minimum, maximum, mean and Std. deviation for each GCC country covering the period of January 2000 to December 2011. The OLS estimator is used to study the impact of the macroeconomic drivers on each GCC country's economic risk. Data are extracted from the International Country Risk Guide files, which offer quantitative measures for each GCC country economic risk assessment on a monthly basis. The study questioned the ability of each GCC's country sub-macroeconomic factors to explain the country specific economic risk. Also, it questioned the casual relationship between each GCC country economic risk and GDP per Head of Population (GDP/HP), Real GDP Growth (RGDPG), Annual Inflation (AI), Budget Balance as Percentage of GDP (BB/GDP), and Current Account as percentage of GDP (CC/GDP).

The descriptive analysis shows that null hypotheses are rejected, indicating that country economic risk formed differently across GCC countries both in mean and Std. deviation, as well as minimum and maximum range. Also, results show that economic risk in GCC countries is driven by different sub-macroeconomic factors across GCC. The highest rating of country economic risk was given by the ICRG to Kuwait, positioning Kuwait as the first choice for capital allocation in GCC. Results show that Kuwait has the highest economic risk rating, lowest economic risk, of 46.40 points $(92.81 \%)$. Regarding KSA, the largest GCC economy, results indicate that it is not a safe home to allocate investment among GCC countries since it has the second worst economic risk before Bahrain.

In conclusion, the null hypotheses, which stated that there is no causal relationship between GCC country's economic risk factor and its sub-macroeconomic drivers is rejected. Therefore, one can say that there is a positive and significant causality relationship between GCC country's economic risk and its sub-macroeconomic factors. These findings give the country risk analysts the opportunity to predict GCC country's economic risk through its components, and to know which subcomponent/s of GCC's economic risk should be monitored closely for early prediction of GCC's economic risk.

Moreover, reported results explore that GCC country's economic risk is driven differently from one country to another. Results indicated that while KSA's economic risk is driven by BB/GDP, Kuwait's economic risk is driven by GDPG; UAE's economic risk is driven by GDP/HP; while Qatar, Oman, and Bahrain economic risk are driven by CC/GDP.

\section{RESEARCH LIMITATION AND DIRECTION FOR FURTHER RESEARCH}

This paper examined the macro-drivers of GCC's countries economic risk, but it was not designed to include micro or related industries variables in the prediction model.

Further research can examine the following: (1) The causal relationship between GCC's composite risk and its specific country economic, financial and political risk; (2) The predictive power of country economic, financial and political risk of market return; (3) The linearity and nonlinearity of country composite, economic, financial and political risk in GCC; (4) The relationship between country risk and stock market capitalization and turn over; (5) The relationship between country risk and financial system creditworthiness. 


\section{ACKNOWLEDGMENT}

I would like to express my appreciation to my colleague at Gulf University for Science and Technology, Dr. Hussein Al Shuroufi, for his grateful and professional editing of my paper.

\section{AUTHOR INFORMATION}

Dr. Hassan Mounir El-Sady is an associate professor of finance at Cairo University's college of commerce (on leave). He is currently visitor professor of finance and the director of continuing and professional education centre at Gulf University for Science \& Technology, Kuwait and the Economic Advisor of Kuwait Stock Exchange. E-mail: Elsady.h@gust.edu.kw and Helsady2020@gmail.com

\section{REFERENCES}

1. Chen, Dar-Hsin, Bin, Feng-Shun and Chen, Chun-Da (2005). The Impacts of Political Events on Foreign Institutional Investors and Stock Returns: Emerging Market Evidence from Taiwan. International Journal of Business, 10 (2).

2. Clark, Ephraim and Radu Tunaru (2001). Emerging market investing with Political risk. Multinational Financial Journal, 5 (3) 155-173.

3. Dar-Hsin Chen, Feng-Shun Bin, and Chun-Da Chen (2005). The Impacts of Political Events on Foreign Institutional Investors and Stock Returns: Emerging Market Evidence from Taiwan. International Journal of Business, (10) 165-188.

4. Diamonte, Robin, Liew, John M. and Stevens, Ross L., (1996). Political risk in emerging and developed markets. Financial Analysts Journal, 52 (3) 9-12.

5. El-Sady, Hassan M., M. Kabir Hassan, Neal c. Maroney, and Ahmed Telfah, A. (2003). Country Risk and Stock Market Volatility, Predictability, and Diversification in the Middle East and Africa. Economic System, (27) 63-82.

6. El-Sady, Hassan M., M. Kabir Hassan, and Oscar Varela, B. (2003). International Country Risk Guide's Country Risk Rating and Emerging Markets' Performance in Latin America. Journal of Emerging Markets, (8) 14-46.

7. El-Sady, Hassan Mounir, M. Kabir Hassan and William Sackley. C. (2003). The Role of Political, Financial and Economic Risk in Governing Volatility and Returns Predictability in Developed Equity Markets. International Journal of Applied Business \& Economic Research, 1 (2) 117-136.

8. El-Sady, Hassan Mounir (2009). The Impact of Country Financial, Economic, and Political Risk on its Creditworthiness and Stock Market Development: Cross Sectional Analysis. Arab Journal of Administrative Sciences, 16 (3) 343-381.

9. Hoti, Suhejla and McAleer, Michael (2004). An Empirical Assessment of Country Risk Ratings and Associated Models. Journal of Economic Surveys, 18 (4) 539-588.

10. Khoury, Sarkis Joseph (2003). Country Risk and International Portfolio Diversification for the Individual Investor. Financial Services Review, (12) 73-93.

11. Onour, Ibrahim A. Ahmed (2007). Impact of Oil Price Volatility on Gulf Cooperation Council Stock Markets' Return. OPEC Review, 31 (3) 171-189.

12. Flannery, Mark J. and Protopapadakis, Aris, (2001). Macroeconomic Factors Do Influence Aggregate Stock Returns. Review of Financial Study, 15 (3) 751-782.

13. Susan K. Schroeder (2008). The Underpinnings of Country Risk Assessment. Journal of Economic Surveys, 22 (3) 498-535.

14. Vij Madhu and Kapoor M. C. (2007). Country Risk Analysis A Case Study of India. Journal of Management Research, 7 (2) 87-102

15. Vij Madhu (2005). The Determinants of Country Risk Analysis An Empirical Approach. Journal of Management Research, 5 (1) 20-31. 